\title{
Efeitos do uso de lodo de estações de tratamento de esgoto sobre a disponibilidade de água em um substrato minerado no Cerrado
}

\author{
Effects of the use of wastewater sludge on water availability \\ of a mine substrate in the Brazilian Savanna
}

Thyego Pery Monteiro de Lima** ${ }^{1 *}$, Rodrigo Studart Corrêa' ${ }^{\circledR}$

口-

\begin{abstract}
RESUMO
A mineração expõe à superfície material genericamente denominado de substrato, que possui atributos físicos, químicos e biológicos diferentes do solo natural. O lodo de estações de tratamento de esgoto (ETE) é a principal fonte de matéria orgânica utilizada na recuperação de áreas mineradas no Distrito Federal. Apesar de as tecnologias de recuperação afetarem positivamente o substrato minerado, seus efeitos sobre a disponibilidade de água para a vegetação foram pouco estudados. Diante disso, este estudo objetivou verificar se a disponibilidade de água em um substrato de mineração de cascalho foi alterada pela aplicação de lodo de ETE. Três materiais foram investigados: substrato minerado sem aplicação de lodo, substrato minerado com aplicação de lodo e solo sob Cerrado original. Esses materiais foram caracterizados por meio da granulometria, densidade aparente, porosidade total, microporosidade, macroporosidade, condutividade hidráulica saturada, teor volumétrico de água à capacidade de campo e ponto de murcha permanente. Posteriormente, monitorou-se, nesses materiais, o teor volumétrico de água e de ar durante 22 semanas. Os resultados indicaram que o substrato minerado armazenou água acima da capacidade de campo durante $86 \%$ do período investigado e o teor de ar permaneceu em níveis críticos durante 55\% do mesmo período. A incorporação de lodo de ETE e a colonização de plantas aumentaram os valores de condutividade hidráulica na saturação (Ksat) e reduziu o período em que a água se manteve armazenada à capacidade de campo. Todavia, o regime de umidade do substrato tratado com lodo de ETE se manteve dissimilar ao do solo original usado como referência.
\end{abstract}

Palavras-chave: disponibilidade de água do solo; substrato minerado; lodo de estação de tratamento de esgoto.

\begin{abstract}
Mining exposes to surface a material generically called substrate, which has different physical, chemical and biological attributes compared to natural soils. The wastewater sludge (WWS) is the main source of organic matter used in reclamation works of mines in the Federal District of Brazil. Reclamation works positively affect mine substrate but their effects on water availability (AW) have been little studied. This work aimed to evaluate the effects of WWS into a mine substrate on its hydraulic conductivity (Ksat) and AW. Samples of a mine substrate exposed to surface, the same material treated with wastewater sludge and soil under natural Savanna vegetation were collected and analyzed for bulk density, granulometry, total porosity, microporosity, macroporosity, saturated Ksat, volumetric water content at field capacity (FC) and at permanent wilt point (PWP). Subsequently, volumetric water and air content were monitored on the field for 22 weeks. Results showed that the substrate exposed by mining presented water content above FC during $86 \%$ of the investigation period and air content at critic levels during 55\% of the same period. The incorporation of WWS and subsequent plant colonization increased Ksat values and shortened the period in which water was store at FC. However, the moisture regime in the substrate treaded with WWS remained dissimilar to that of the original soil used as reference.
\end{abstract}

Keywords: soil water availability; mine substrate; wastewater sludge.

\section{INTRODUÇÃO}

A exploração mineral expõe à superfície material genericamente denominado de substrato, que possui atributos físicos, químicos e biológicos diferentes do solo natural, que dificultam o processo de sucessão ecológica (CORRÊA, 2009). As modificações provocadas pelo revolvimento na estrutura do solo, pela distribuição do tamanho dos poros e pelo teor de carbono orgânico do

'Programa de Pós-Graduação em Ciências Ambientais, Universidade de Brasília - Planaltina (DF), Brasil.

*Autor correspondente: pery.monteiro@gmail.com

Conflitos de interesse: os autores declaram que não há conflito de interesse.

Financiamento: Conselho Nacional de Desenvolvimento Científico e Tecnológico (CNPq), Edital Universal MCTI/CNPq n 14/2014.

Recebido: 18/01/2O19 - Aceito: 12/O2/2O2O - Reg. ABES: 20190016 
solo alteram as forças de retenção de água e a sua respectiva disponibilidade (SILVA et al., 2005).

As atividades de recuperação de áreas degradadas pela mineração envolvem tipicamente a melhoria dos atributos físicos dos substratos expostos, tais como reduzir a densidade aparente e aumentar a porosidade deles. Além disso, o processo de reabilitação de substratos minerados envolve também a introdução de nutrientes e de matéria orgânica, proporcionando condições favoráveis ao estabelecimento de uma comunidade vegetal e iniciando o processo de sucessão ecológica.

O lodo produzido em estações de tratamento de esgoto (ETE) é uma fonte de matéria orgânica economicamente vantajosa para ser incorporada a substratos minerados, principalmente em razão de sua grande disponibilidade e das menores restrições sanitárias para utilizá-lo em relação à agricultura, à jardinagem e à pecuária (CORRÊA, 2009). Oliveira (2015) corroborou a eficiência do lodo de esgoto em melhorar as propriedades físicas e a fertilidade de substratos minerados tratados com lodo de esgoto ao avaliar a textura, a densidade de partículas, a densidade do solo, as concentrações de carbono, nitrogênio, carbono da biomassa microbiana e respiração basal nesses materiais.

Bento (2009) avaliou substratos minerados recuperados por meio da aplicação de lodo de ETE no Distrito Federal e constatou melhorias significativas em seus atributos físicos, químicos e biológicos. Ainda que houvesse registrado melhora nos atributos físicos, Bento (2009) aponta que esses foram os atributos que menos se assemelhavam às características originais do solo. Observações similares foram realizadas por Corrêa e Bento (2010), que avaliaram a qualidade edáfica de um substrato minerado revegetado com o uso de lodo de esgoto e concluíram que o substrato minerado com aplicação de lodo apresentou a metade da capacidade de armazenar água do solo sob Cerrado.

Apesar de as tecnologias de recuperação afetarem positivamente o solo degradado, seus efeitos sobre o regime de umidade do solo são insuficientemente compreendidos (CEJPEK; KURÁŽ; FROUZ, 2013), e isso se refere à disponibilidade de água para a vegetação durante períodos específicos de tempo (BRADY; WEIL, 2013).

No bioma Cerrado, há um período de estiagem de cinco meses a cada ano, quando a disponibilidade de água é um fator crítico para o desenvolvimento de comunidades vegetais (CORRÊA, 2009). Apesar disso, poucos estudos abordam o comportamento da água disponível em jazidas revegetadas. Em face do exposto, este estudo objetivou avaliar a disponibilidade de água em um substrato de mineração que fora tratado com lodo de ETE e revegetado.

\section{METODOLOGIA}

\section{Área de estudo}

O estudo ocorreu em uma jazida explorada para a retirada de cascalho e tratada com lodo de ETE antes de sua revegetação. A jazida está localizada às margens do km 15,5 da rodovia BR-060, sentido Brasília - Goiânia, no Distrito Federal

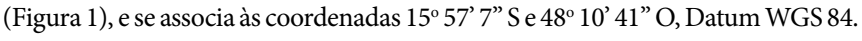

O terreno original da jazida apresentava topografia variando de plana a plano-ondulada, em cota acima de $1.000 \mathrm{~m}$, onde se desenvolvia vegetação de Cerrado sentido restrito (SILVA et al. (2013) sobre Cambissolo Háplico (EMBRAPA, 2013). Cascalho laterítico é explorado em áreas cobertas por Cambissolo no Distrito Federal. O clima predominante no Distrito Federal é o Tropical de Savana (Aw - Köppen-Geiger), com precipitação média anual variando de 1.200 a $1.600 \mathrm{~mm}$, com $84 \%$ do volume precipitado no verão. A temperatura média mensal oscila entre 19 e $22^{\circ} \mathrm{C}$ e a umidade relativa do ar média anual é de 66\% (INMET, 2018; PEEL; FINLAYSON; MCMAHON, 2007).

As escavações para a extração de cascalho expuseram uma superfície plana de 4 a $6 \mathrm{~m}$ abaixo do nível original do terreno (Figura 2) em 2002. O lodo de esgoto foi depositado em lâminas sobre a superfície minerada por meio de basculamento do material produzido na Estação de Tratamento de Esgoto Brasília Norte (ETEB Norte), sempre com os caminhões em movimento (Figura 2).

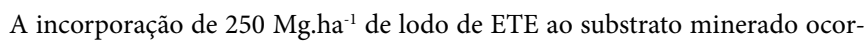
reu ainda no ano de 2002, após autorização emitida pelo órgão ambiental local após análise do Plano de Recuperação da Área Degradada (PRAD). Uma grade aradora leve foi utilizada para incorporar o lodo de esgoto ao substrato exposto entre 0 e $15 \mathrm{~cm}$ de profundidade (Figura 2).

\section{Características do lodo}

O lodo aplicado na área de estudo foi produzido na Estação de Tratamento de Esgoto Brasília Norte (ETEB Norte) a partir da coleta e do tratamento de esgotos domésticos. A ETEB Norte é operada pela Companhia de Saneamento Ambiental do Distrito Federal (CAESB), produzindo $60 \mathrm{Mg} \cdot \mathrm{dia}^{-1}$ de lodo desaguado, originado do tratamento primário (decantador), secundário (lodo ativado) e terciário (floculação/flotação com sulfato de alumínio e polímero). Esses três tipos de lodo são misturados e encaminhados para digestão anaeróbia. Após essa etapa, o lodo é desaguado em uma prensa mecânica e encaminhado para estocagem, contendo entre 86 e $88 \%$ de água (Tabela 1).

\section{Delineamento experimental}

Nesta pesquisa, foram utilizados substrato exposto pela mineração sem aplicação de lodo, substrato exposto pela mineração com aplicação de lodo e solo sob Cerrado original. Esses materiais foram inicialmente coletados e caracterizados em triplicata para granulometria, densidade aparente (base úmida), porosidade total, microporosidade, macroporosidade, condutividade hidráulica na saturação (Ksat), teor volumétrico de água à capacidade de campo (CC) e teor volumétrico de água $(\theta \mathrm{v})$ ao ponto de murcha permanente (PMP). A densidade aparente foi determinada pelo método do anel volumétrico; a granulometria, pelo método da pipeta; e a CC e o PMP foram determinados pelo método do extrator de Richards no laboratório da Campo Fertilidade do Solo e Nutrição Vegetal, em Paracatu, Minas Gerais, conforme métodos estabelecidos por Embrapa (1997). Em seguida, mensurou-se in loco o $\theta \mathrm{v}$ e o teor volumétrico de ar desses materiais entre 16 de dezembro de 2017 e 12 de maio de 2018, totalizando 22 semanas de monitoramento.

A Ksat foi mensurada com um infiltrômetro de tensão Mini Disk em quatro pontos na superfície do solo sob Cerrado, em 12 pontos na superfície do substrato minerado com aplicação de lodo e em 11 pontos na superfície do substrato minerado sem aplicação de lodo, de acordo com a homogeneidade dos dados, totalizando 27 medições na área de estudo.

A porosidade total foi estimada pela relação entre a densidade aparente $\mathrm{e}$ a densidade de partículas, conforme Reichardt e Timm (2012). A microporosidade foi considerada como o $\theta \mathrm{v}$ retida pelo solo na tensão de $6 \mathrm{kPa}$, conforme Reichardt e Timm (2012). Por sua vez, a macroporosidade foi calculada por meio da diferença entre porosidade total e microporosidade (EMBRAPA, 1997). 


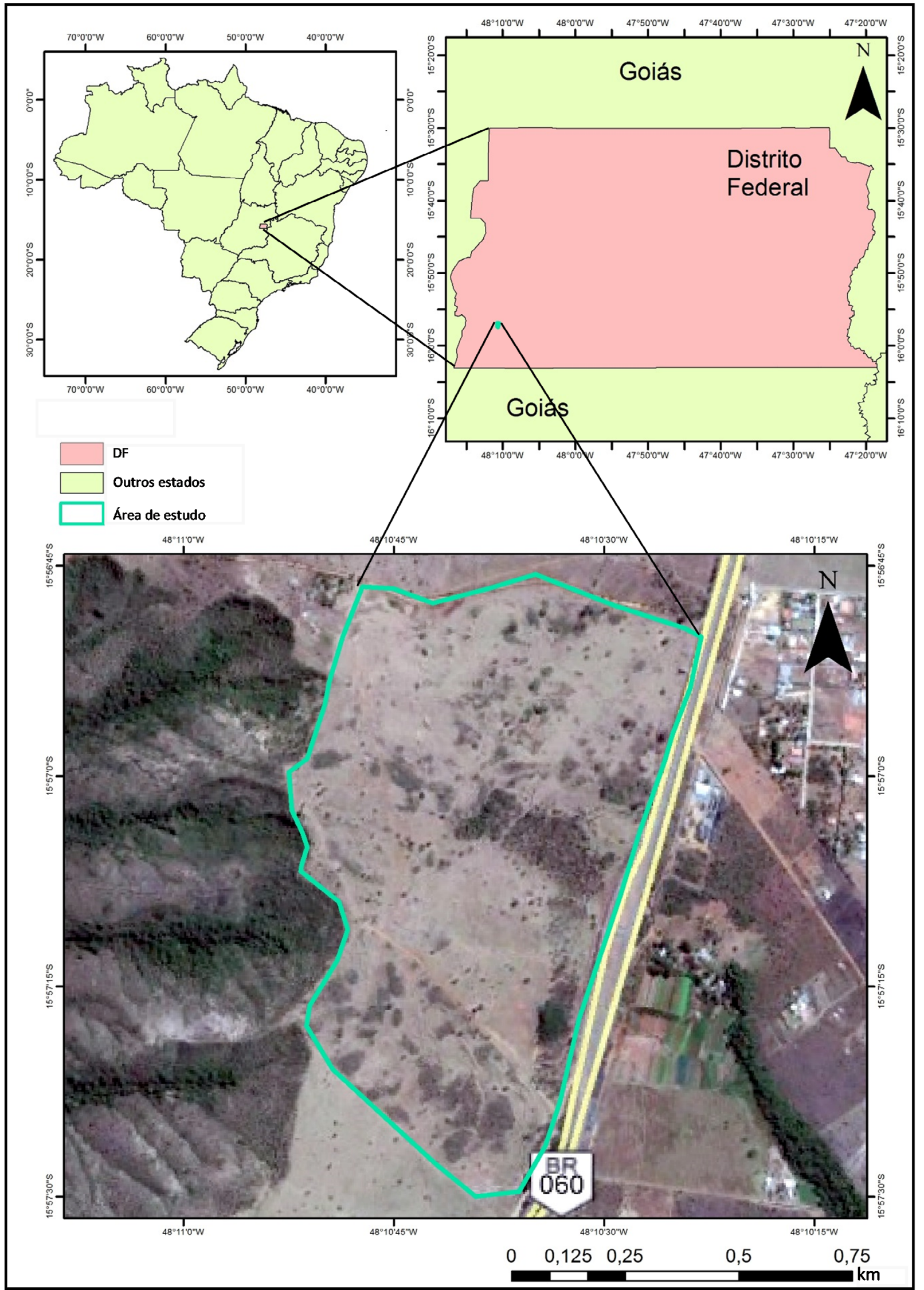


A determinação do $\theta \mathrm{v}$ foi semanalmente mensurado por meio de um sensor de umidade Eijkelkamp 5201, conectado a blocos de resistência elétrica fabricados em gesso e instalados nos substratos e no solo (BRADY; WEIL, 2013; REICHARDT; TIMM, 2012). Cada tratamento recebeu 30 blocos de gesso, totalizando 90 blocos instalados. A mensuração da porosidade total e do $\theta v$ permitiu a obtenção do teor volumétrico de ar, conforme Libardi (2000).

\section{Análise estatística}

Os dados foram tabulados e procedeu-se à ANOVA de fator único, com nível de significância < 0,05, conforme sugerido por Fávero et al. (2009) e Field (2009). Complementarmente à ANOVA, realizou o teste de Tukey, com nível de significância $<0,05$. ANOVA e teste de Tukey foram realizados por meio do software R (R CORE TEAM, 2018), pacote “vegan” (OKSANEN et al., 2018).

\section{RESULTADOS E DISCUSSÃO}

A aplicação do lodo possibilitou a redução de aproximadamente $40 \%$ da densidade aparente (base úmida) apresentada pelo substrato minerado, o que pode
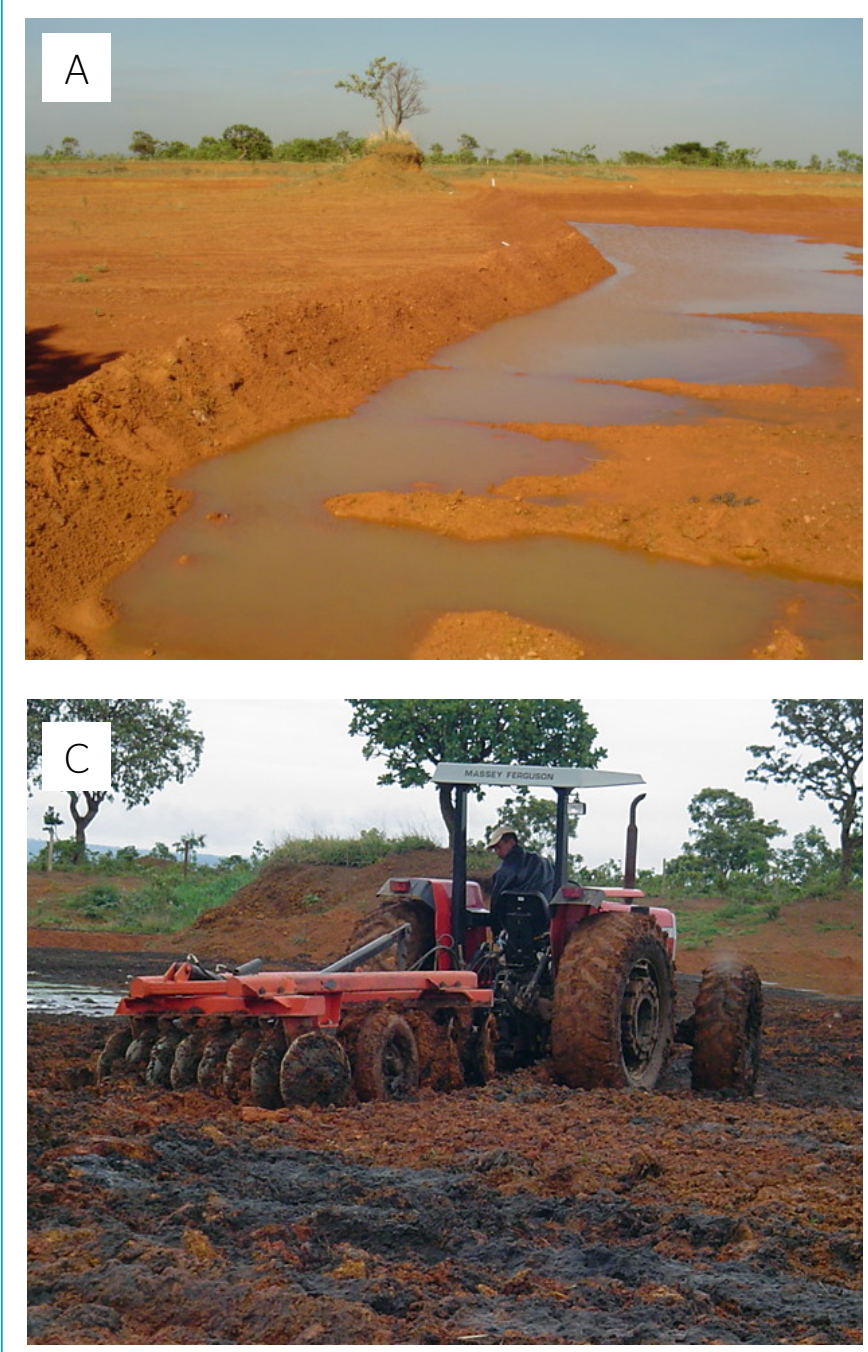

Fonte: (A e B) Rodrigo Studart Corrêa; (C) Henrique Cruvinel; (D) Thyego Pery. ser verificado ao se comparar os dados obtidos para substrato com aplicação de lodo e o substrato sem a aplicação da mesma fonte de matéria orgânica (Tabela 2). Resultado semelhante foi observado por Corrêa e Bento (2010). A redução na densidade aparente resulta do aumento na porosidade propiciada

Tabela 1 - Principais características do lodo gerado na estação de tratamento de esgoto, Brasília Norte.

\begin{tabular}{l|c|c|c} 
Atributo & Base & Unidade & Valor \\
\hline Teor de água & úmida & $\%$ & $86-88$ \\
\hline Sólidos totais & úmida & $\mathrm{g} \cdot \mathrm{kg}^{-1}$ & $120-140$ \\
\hline Sólidos totais fixos & úmida & $\mathrm{g} \cdot \mathrm{kg}^{-1}$ & $31-34$ \\
\hline Sólidos totais voláteis & úmida & $\mathrm{g} \cdot \mathrm{kg}^{-1}$ & $89-106$ \\
\hline Densidade aparente & úmida & $\mathrm{Mg} \cdot \mathrm{m}^{-3}$ & $1,1-1,2$ \\
\hline Carbono total & seca & $\mathrm{g} \cdot \mathrm{kg}^{-1}$ & $310-330$ \\
\hline Nitrogênio Total Kjeldahl & seca & $\mathrm{g} \cdot \mathrm{kg}^{-1}$ & $51-59$ \\
\hline Fósforo total & seca & $\mathrm{g} \cdot \mathrm{kg}^{-1}$ & $31-38$ \\
\hline Alumínio total & seca & $\mathrm{g} \cdot \mathrm{kg}^{-1}$ & $2,3-3,7$ \\
\hline
\end{tabular}
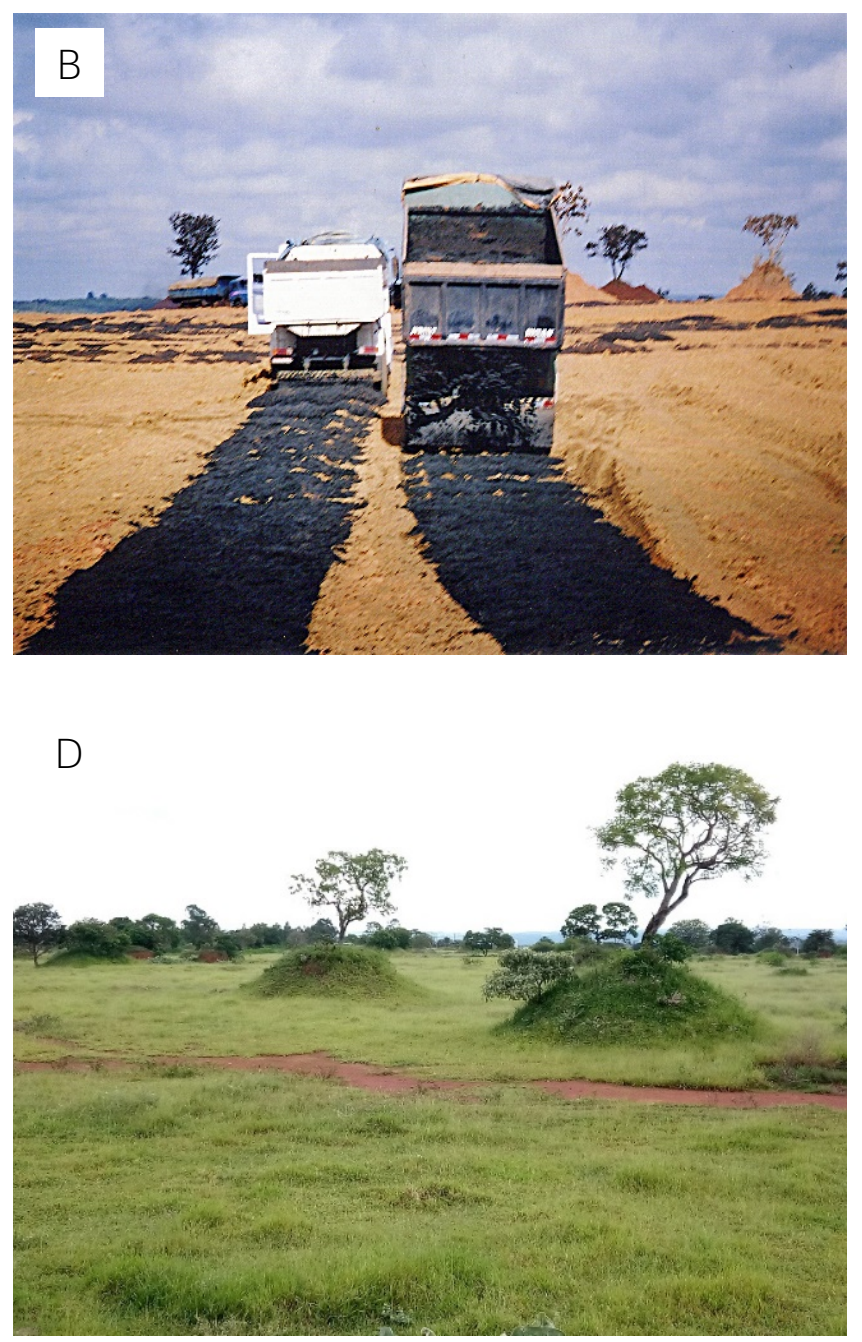

Figura 2 - (A) Substrato minerado após a exploração de cascalho; (B) deposição de lodo de esgoto por caminhões sobre o substrato minerado; (C) incorporação do lodo de esgoto ao substrato minerado; (D) área revegetada 16 anos após a aplicação de lodo de estações de tratamento de esgoto. 
pela incorporação de matéria orgânica. Esse fenômeno é corroborado ao observar o aumento de quase $50 \%$ na porosidade total do substrato tratado com lodo em relação ao substrato que não foi submetido ao mesmo tratamento. A macroporosidade e a microporosidade medidas após a aplicação de lodo e da revegetação do substrato exposto pela mineração aumentaram significativamente e não diferiram $(\mathrm{p}<0,05)$ dos valores medidos no solo sob Cerrado sentido restrito. Isso mostra que a aplicação da fonte de matéria orgânica em questão resultou em condições bastante similares àquelas encontradas em um solo não perturbado da mesma região, considerando essas variáveis específicas.

A granulometria do substrato sem lodo e do substrato com lodo não apresentou diferenças estatisticamente significativas para a maioria das frações determinadas. Entretanto, o solo sob Cerrado apresentou perfil granulométrico distinto. Sabe-se que o processo de pedogênese se relaciona com cinco fatores: clima, relevo, organismos, material de origem e tempo (KER et al., 2015). Considerando que os fatores como clima, relevo e material de origem são semelhantes entres os materiais estudados, cabe destacar que ele não pode ser afirmado para o fator tempo de exposição às intempéries. O substrato com aplicação de lodo possui apenas 15 anos de desenvolvimento, se for considerado que seu processo pedogenético iniciou após a aplicação de lodo. Antes, esse material era estéril e sem a presença de organismos que aceleram a pedogênese. $\mathrm{O}$ solo sob Cerrado possui tempo muito maior de evolução e a quantidade maior de argila é um reflexo disso. Um dos resultados da intemperização do solo é o aumento do teor de argila (KER et al., 2015).

Todos os atributos anteriormente citados (Tabela 2) influenciaram a Ksat dos materiais. O substrato minerado apresentou Ksat de $52 \mathrm{~mm} \cdot \mathrm{h}^{-1} \mathrm{e}$ a incorporação de lodo permitiu que esse valor aumentasse em mais de $300 \%$. Ainda que a Ksat do substrato com aplicação de lodo não tenha atingido valor similar ao do solo sob Cerrado, esse aumento expressivo representa uma atenuação de um dos principais problemas ambientais em áreas mineradas: a erosão causada pelo escoamento superficial de águas pluviais como resultado da baixa capacidade de infiltração de água no solo. O aumento da Ksat no substrato tratado com lodo pode ser explicado pelo aumento da porosidade total e pela diminuição da densidade aparente apresentada por esse material após a incorporação do lodo.
A camada superficial do solo sob Cerrado é mais argilosa do que os substratos expostos pela mineração e, portanto, esperava-se menor Ksat nesse material, o que não ocorreu. A estrutura granular pequena a muito pequena de solos da região do Cerrado confere boa permeabilidade a esses materiais (COSTA et al., 1999; MAIA, 2016; REATTO et al., 2007). Resultados similares foram observados por Cunha et al. (2015) e Ramos et al. (2013), que observaram que solos do Cerrado com os maiores teores de argila apresentaram as maiores valores de Ksat.

Os diferentes valores de Ksat observados neste trabalho resultaram em diferentes classificações de condutividade hidráulica. Considerando Soil Science Division Staff (2017), verifica-se que a Ksat do solo sob Cerrado é considerada "muito rápida", enquanto a Ksat do substrato com lodo é "moderada a rápida". Por sua vez, a Ksat do substrato minerado sem aplicação de lodo é classificada como "lenta a moderada".

O substrato minerado com aplicação de lodo apresentou valor 16\% maior de água disponível ( $\mathrm{AD}$ = CC - PMP) em relação ao substrato minerado sem aplicação da mesma fonte de matéria orgânica. Sob uma abordagem estatística, pode-se afirmar que a quantidade de água disponibilizada pelo substrato com aplicação de lodo é similar à quantidade de água disponibilizada pelo solo sob Cerrado, reforçando novamente os ganhos ambientais desse tratamento. O aumento de água disponível é explicado pelo aumento significativo da microporosidade após o processo de revegetação. Com maior quantidade de poros, o substrato tratado com lodo apresentou maior quantidade de espaços vazios que podem ser preenchidos pela água após a precipitação de águas pluviais e, consequentemente, disponibilizar maior quantidade de água a ser utilizada pela vegetação. Resultados similares foram obtidos por Corrêa e Bento (2010), que relataram aumento na água disponível de um substrato com incorporação de lodo em relação ao substrato sem incorporação dessa fonte de matéria orgânica.

\section{Teor volumétrico de água e de ar}

As diferentes características observadas no substrato minerado com e sem aplicação de lodo e no solo sob Cerrado proporcionaram distintos comportamentos da água pluvial nesses materiais (Figura 3).

Tabela 2 - Caracterização do substrato minerado sem aplicação de lodo, do substrato minerado com aplicação de lodo e do solo sob Cerrado'.

\begin{tabular}{|c|c|c|c|c|}
\hline \multicolumn{2}{|l|}{ Variável } & $\begin{array}{l}\text { Substrato minerado sem } \\
\text { aplicação de lodo }\end{array}$ & $\begin{array}{l}\text { Substrato minerado com } \\
\text { aplicação de lodo }\end{array}$ & Solo sob Cerrado \\
\hline \multicolumn{2}{|c|}{ Densidade aparente (base úmida, ${\mathrm{Mg} \cdot \mathrm{m}^{-3} \text { ) }}$} & 1,43a & $0,84 b$ & $0,97 b$ \\
\hline \multirow{3}{*}{ Porosidade $\left(\mathrm{m}^{3} \cdot \mathrm{m}^{-3}\right)$} & Total & $0,46 a$ & $0,68 \mathrm{~b}$ & $0,63 \mathrm{~b}$ \\
\hline & Microporosidade & $0,12 a$ & $0,2 \mathrm{Ob}$ & $0,19 b$ \\
\hline & Macroporosidade & $0,34 a$ & $0,48 b$ & $0,45 a b$ \\
\hline \multirow{4}{*}{ Granulometria (\%) } & Areia grossa & $33,20 \mathrm{a}$ & 28,90a & $17,60 b$ \\
\hline & Areia fina & 11,10a & $8,10 b$ & $3,60 \mathrm{c}$ \\
\hline & Silte & 29,10ab & $37 a$ & $21,10 b$ \\
\hline & Argila & 26,70a & $26 a$ & $57,70 b$ \\
\hline \multicolumn{2}{|l|}{ Ksat $\left(m m \cdot h^{-1}\right)$} & $52 \mathrm{a}$ & $213 b$ & $356 c$ \\
\hline \multirow{2}{*}{ Teor volumétrico de água $\left(\mathrm{m}^{3} \cdot \mathrm{m}^{-3}\right)$} & $\mathrm{CC}$ & $0,27 a$ & $0,40 b$ & $0,33 c$ \\
\hline & PMP & $0,21 \mathrm{a}$ & $0,34 b$ & $0,25 a$ \\
\hline \multicolumn{2}{|l|}{ Faixa de água disponível $\left(\mathrm{m}^{3} \cdot \mathrm{m}^{-3}\right)$} & $0,06 a$ & $0,07 \mathrm{~b}$ & $\mathrm{O}, 08 \mathrm{~b}$ \\
\hline
\end{tabular}

CC: capacidade de campo; PMP: ponto de murcha permanente; 'valores seguidos pela mesma letra na linha não diferem significativamente pelo teste de Tukey. 
O solo sob Cerrado foi o material que manteve o $\theta \mathrm{v}$ disponível para as plantas por mais tempo, mais especificamente por $68 \%$ do período de investigação. Nenhum dos outros dois materiais investigados mantiveram água armazenada por tanto tempo entre o PMP e a CC. O substrato sem lodo e o substrato com lodo apresentaram comportamentos opostos. O substrato sem aplicação de lodo apresentou $\theta \mathrm{v}$ acima da CC de forma prolongada, especificamente por 86\% do período de investigação, apontando para um excesso de água armazenada nesse material durante o período de investigação. O substrato com aplicação de lodo apresentou teor de água abaixo do PMP durante 77\% do tempo no mesmo período, indicando que esse material esteve excessivamente seco.

O substrato minerado sem aplicação de lodo é um material mais arenoso e suas partículas não exercem tensão suficiente para impedir o fluxo gravitacional da água. Logo, o excesso de água observado nesse material indica que sua condutividade hidráulica se mantém muito baixa ao longo do seu perfil. Isso resulta em má permeabilidade das águas pluviais, como foi observado.

Motivos similares explicariam o baixo teor de água apresentado pelo substrato minerado com aplicação de lodo. O substrato tratado com lodo também possui quantidade expressiva de areia e pouca argila. Dessa forma, sua capacidade de reter água é tão limitada quanto a do substrato minerado sem lodo. Entretanto, o substrato tratado com lodo de esgoto apresentou Ksat significativamente maior que o substrato não tratado com esse resíduo. A provável

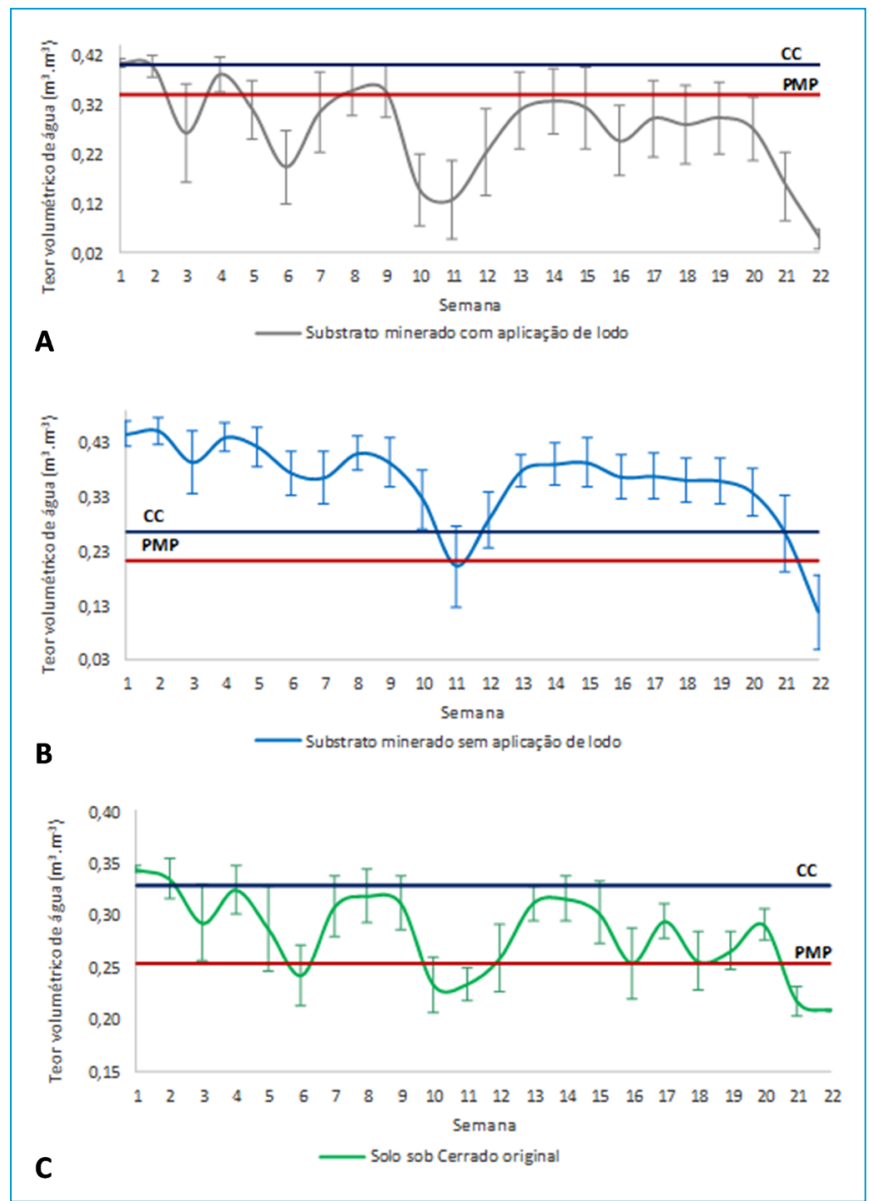

PMP: ponto de murcha permanente; CC: capacidade de campo.

Figura 3 - Teor volumétrico de água $\left(\mathrm{m}^{3} \cdot \mathrm{m}^{-3}\right)$ ao longo de 22 semanas de observação: (A) substrato minerado sem aplicação de lodo; (B) substrato minerado com aplicação de lodo; (C) solo sob Cerrado original. combinação entre a baixa tensão exercida pelas partículas de areia e silte do substrato tratado com lodo sobre a água e a grande permeabilidade desse material explicam o baixo teor de água armazenada à CC.

A má aeração do substrato minerado sem aplicação de lodo, como pode ser verificado na Figura 4, é outro fator que pode constatar um regime de saturação prolongada. Brady e Weil (2013) afirmam que, em casos em que a quantidade de poros preenchidos por ar for menor que $20 \%$ do espaço poroso, a atividade microbiana e o crescimento de plantas são severamente afetados.

O solo sob Cerrado e o substrato tratado com lodo não apresentaram porosidade preenchida por ar em níveis inferiores a $20 \%$ da porosidade total $\left(0,13 \mathrm{~m}^{3} \cdot \mathrm{m}^{-3}\right.$ para solo sob Cerrado e $0,14 \mathrm{~m}^{3} \cdot \mathrm{m}^{-3}$ para substrato com lodo). Entretanto, o substrato minerado apresentou níveis inferiores a $20 \%$ da porosidade total $\left(0,09 \mathrm{~m}^{3} \cdot \mathrm{m}^{-3}\right)$ durante $55 \%$ do período estudado. O baixo teor volumétrico de ar no substrato minerado é resultado do excesso de água nesse material, fato que não ocorreu no substrato tratado com lodo e no solo sob Cerrado.

Os resultados obtidos evidenciam que o substrato sem aplicação de lodo, o substrato com aplicação de lodo e o solo sob Cerrado apresentam regimes de umidade distintos. Considerando as classes propostas por Brady e Weil (2013), o substrato sem lodo apresentou comportamento áquico, pois permaneceu saturado por água e praticamente livre de oxigênio gasoso por tempo suficiente para apresentar indícios de má aeração. Segundo Reatto et al. (2004) e Haridasan (1993), a ocorrência natural de solos com essas características (solos hidromórficos) no Distrito Federal representa menos que 5\% de sua área geográfica.

O substrato tratado com lodo, por sua vez, apresentou $\theta v$ abaixo do PMP na maior parte do período de crescimento da vegetação. Quando foi umedecido pelas águas pluviais, esse material permaneceu com água disponível por menos de 90 dias consecutivos durante a estação chuvosa. Segundo os critérios estabelecidos por Brady e Weil (2013), o regime de umidade do substrato com aplicação de lodo é o arídico.

O solo sob Cerrado, condição natural que se tenta reproduzir, não está submetido à saturação prolongada por água e permanece com água disponível para as plantas na maior parte do período chuvoso (Figura 3). Considerando a existência de água disponível em parte do ano e que ocorre um período significativo de estiagem que caracteriza a região do Cerrado, o regime de umidade do solo sob Cerrado investigado é classificado como ústico (BRADY; WEIL, 2013). Nessa perspectiva, Buol (2009) ressalta que a maioria dos solos do Cerrado possui esse regime de umidade.

Um dos aspectos que define a fitofisionomia de Cerrado em determinado solo é o grau e a duração de saturação por água da camada superficial ou subsuperficial

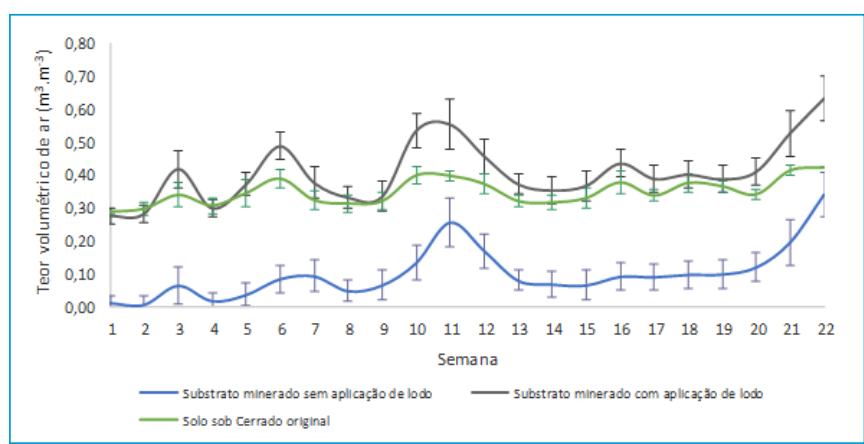

Figura 4 - Teor volumétrico de $\operatorname{ar}\left(\mathrm{m}^{3} \cdot \mathrm{m}^{-3}\right)$ do substrato minerado sem aplicação de lodo, do substrato minerado com aplicação de lodo e do solo sob Cerrado original em 22 semanas de observação. 
(EITEN, 1993). Considerando que os dois substratos de mineração e o solo sob Cerrado apresentaram diferentes regimes de umidade, estima-se que diferentes fitofisionomias serão estabelecidas em cada um desses locais. Nesse sentido, o processo de revegetação com uso de lodo de esgoto está conduzindo a sucessão ecológica no sentido do desenvolvimento de uma fitofisionomia diferente daquela que existia na área de estudo antes da mineração. Apesar disso, a vegetação estabelecida na área reflete a recuperação da sua capacidade produtiva. Conhecer o regime de umidade de substratos revegetados por meio da aplicação de lodo de esgoto pode proporcionar escolhas mais adequadas ao longo do processo de recuperação de uma área. $\mathrm{O}$ aumento da condutividade hidráulica do substrato exposto pela mineração pode facilitar o estabelecimento de uma vegetação mais próxima daquela que originalmente existia na área.

\section{CONCLUSÕES}

Os atributos mensurados no substrato minerado sem aplicação de lodo, no substrato com aplicação de lodo e no solo sob Cerrado mostraram que eles apresentam diferentes regimes de umidade. Os valores obtidos mostram diferenças significativas nas taxas de infiltração de água e no período em que os materiais estudados se mantêm úmidos.

Nesse sentido, o substrato minerado que recebeu lodo de esgoto apresentou volume de água disponível $16 \%$ maior do que o substrato minerado que não foi tratado com lodo de esgoto. $\mathrm{O}$ substrato exposto pela mineração apresentou regime de umidade áquico, e após receber lodo de esgoto e ser colonizado por plantas, passou a apresentar regime de umidade arídico.

Apesar de alterar o regime de umidade do substrato e permitir o reestabelecimento de vegetação na área degradada, a incorporação do lodo de ETE não foi capaz de proporcionar um regime de umidade similar ao do solo original, que existia antes da exploração mineral. O regime de umidade do solo sob Cerrado foi classificado como ústico, que disponibiliza uma quantidade maior de água para a vegetação.

\section{CONTRIBUIÇÕES DOS AUTORES}

Lima, T.P.M.: Conceituação, Curadoria de Dados, Análise Formal, Escrita - Primeira Redação. Corrêa, R.S.: Conceituação, Metodologia, Escrita - Revisão e Edição.

\section{REFERÊNCIAS}

BENTO, M.A.B. Avaliação da qualidade dos substratos minerados em cinco cascalheiras revegetadas no Distrito Federal. 218f. Dissertação (Mestrado) Universidade de Brasília, Brasília, 2009.

BRADY, N.C.; WEIL, R.R. Elementos da Natureza e Propriedades dos Solos. 3. ed. Porto Alegre-RS: Bookman, 2013. 686 p.

BUOL, S.W. Soils and agriculture in central-west and north Brazil. Scientia Agricola, v. 66, n. 5, p. 697-707, 2009. https://doi.org/10.1590/S010390162009000500016

CEJPEK, J.; KURÁŽ, V.; FROUZ, J. Hydrological Properties of Soils in Reclaimed and Unreclaimed Sites after Brown-Coal Mining. Polish Journal of Environmental Studies, v. 22, n. 3, p. 645-652, 2013.

CORREAA, R.S. Recuperação de Areas Degradadas pela Mineração no Cerrado. 2. ed. Brasília: Universa, 2009. 174 p.

CORREAA, R.S.; BENTO, M.A.B. Qualidade do substrato minerado de uma área de empréstimo revegetada no Distrito Federal. Revista Brasileira de Ciência do Solo, v. 34, n. 4, p. 1435-1443, 2010. https://doi.org/10.1590/SO10006832010000400039

COSTA, E.L. et al. Infiltração de água em solo, determinada por simulador de chuvas e pelo método dos anéis. Revista Brasileira de Engenharia Agrícola e Ambiental, v. 3, n. 2, p. 131-134, 1999. https://doi.org/10.1590/18071929/agriambi.v3n2p131-134

CUNHA, J.L.X.L. et al. Water infiltration rate in Yellow Latosol under different soil management systems. Revista Brasileira de Engenharia Agrícola e Ambiental, v. 19, n. 11, p. 1021-1027, 2015. https://doi.org/10.1590/1807-1929/ agriambi.v19n11p1021-1027

EITEN, G. Vegetação. In: PINTO, M.N. (org.). Cerrado: caracterização, ocupação e perspectivas. 2. ed. Brasília: Editora Universidade de Brasília, 1993. 681 p.
EMPRESA BRASILEIRA DE PESQUISA AGROPECUÁRIA (EMBRAPA). Manual de Métodos e Análise de Solo. 2. ed. Rio de Janeiro: Embrapa-CNPS, 1997. 212 p.

EMPRESA BRASILEIRA DE PESQUISA AGROPECUÁRIA (EMBRAPA) Sistema Brasileiro de Classificação de Solos. 3. ed. Brasília: Embrapa Informação Tecnológica, 2013. 3535 p.

FÁVERO, L.P. et al. Análise de dados: modelagem multivariada para tomada de decisões. Rio de Janeiro: Elsevier, 2009. 646 p.

FIELD, A. Descobrindo a estatística usando o SPSS. 2. ed. Porto Alegre: Artmed, 2009. 688 p.

HARIDASAN, M. Solos. In: PINTO, M.N. (org.). Cerrado: caracterização, ocupação e perspectivas. Brasília: Editora Universidade de Brasília, 1993. 681 p.

INSTITUTO NACIONAL DE METEOROLOGIA (INMET). Normal Climatológica do Brasil 1981-2010. INMET. Disponível em: http://www.inmet.gov.br/portal/ index.php?r=clima/normaisClimatologicas. Acesso em: 14 dez. 2018.

KER, J.C. et al. Pedologia: fundamentos. Viçosa: Sociedade Brasileira de Ciência do Solo, 2015. 343 p.

LIBARDI, P.L. Dinâmica da água no solo. 2. ed. Piracicaba: ESALQ/USP, 2000. $509 p$

MAIA, F.C.O. Curva de retenção e capacidade de água disponivel em Latossolos. Monografia (Graduação) - Universidade de Brasília, Brasília, 2016.

OKSANEN, J. et al. Vegan: Community Ecology Package. Disponível em: https://cran.r-project.org/package=vegan. Acesso em: 2018.

OLIVEIRA, D.N.S. Efeito do lodo de esgoto e de plantas de cobertura na recuperação de uma área degradada em Brasilia-DF. 61f. Dissertação (Mestrado) - Universidade de Brasília, Brasília, 2015. 
PEEL, M.C.; FINLAYSON, B.L.; MCMAHON, T.A. Updated world map of the Köppen-Geiger climate classification. Hydrology and Earth System Sciences, v. 11, p. 1633-1644, 2007. https://doi.org/10.5194/hess-11-1633-2007

RAMOS, B.Z. et al. Avaliação dos atributos físico-hídricos em um Latossolo Vermelho distroférrico sob diferentes sistemas de manejo Lavras / Minas Gerais / Brasil. Revista de Ciências Agrárias, v. 36, n. 3, p. 340-346, 2013.

R CORE TEAM. R: A language and environment for statistical computing. Viena: R Foundation for Statistical Computing. Disponível em: http://www.rproject.org/. Acesso em: 2018.

REATTO, A. et al. Hydraulic properties of the diagnostic horizon of Latosols of a regional toposequence across the Brazilian Central Plateau. Geoderma, v. 139, n. 1-2, p. 51-59, 2007. https://doi.org/10.1016/j. geoderma.2007.01.003
REATTO, A. et al. Mapa pedológico digital: SIG atualizado do Distrito Federal escala 1:100.000 e uma síntese do texto explicativo. Planaltina, 2004

REICHARDT, K.; TIMM, L.C. Solo, Planta e atmosfera: conceitos, processos e aplicações. 2. ed. Barueri: Manole, 2012. 500 p.

SILVA, L.C.R. et al. Unprecedented carbon accumulation in mined soils: The synergistic effect of resource input and plant species invasion. Ecological Applications, v. 23, n. 6. p. 1345-1356, 2013. https://doi.org/10.1890/12-1957.1

SILVA, M.A.S. et al. Atributos físicos do solo relacionados ao armazenamento de água em um Argissolo Vermelho sob diferentes sistemas de preparo. Ciência Rural, v. 35, n. 3, p. 544-552, 2005. https://doi.org/10.1590/S010384782005000300009

SOIL SCIENCE DIVISION STAFF. Soil Survey Manual. 18. ed. Washington, D.C.: United States Department of Agriculture, 2017. 639 p. 